\begin{tabular}{|c|c|}
\hline $\begin{array}{c}\text { European Association for the } \\
\text { Development of Renewable Energies, Environment } \\
\text { and Power Quality (EA4EPQ) }\end{array}$ & $\begin{array}{c}\text { International Conference on Renewable Energies and Power Quality } \\
\text { (ICREPQ'12) }\end{array}$ \\
Santiago de Compostela (Spain), 28th to 30th March, 2012
\end{tabular}

\title{
Control Strategies for a Power Electronic Based Fault Current Limiter (FCL) in No-Fault Operation
}

\author{
Manuel Weiland, Christoph Hahn, Gerhard Herold \\ Institute of Electrical Power Systems \\ University of Erlangen-Nuremberg \\ Cauerstraße 4 - Bldg. 1, D-91058 Erlangen, Germany \\ Phone/Fax number: +49 9131 85295-27/41, e-mail: weiland@eev.eei.uni-erlangen.de
}

\begin{abstract}
Fault current limiters (FCL) in electrical power systems offer the opportunity to reduce short-circuit stresses to the system in the case of faults. But as electrical power systems are normally operated without faults most of the time, FCLs must not have negative effects during these periods of normal operation. The FCL investigated in this paper is based on a 6-pulse current converter. As every other current converter this type of FCL can introduce additional system perturbations in form of higher harmonics. The aim of this work is to develop appropriate strategies to control the FCL in a way that virtually no additional system perturbations are introduced by the FCL under normal no-fault conditions. In electrical three-phase systems this means simply, the controller has to provide sinusoidal current waveforms.
\end{abstract}

\section{Keywords}

FCL, converter control, short-circuit, thyristor converter

\section{Introduction}

In this paper a power electronic based FCL is investigated. Thereby the term "power electronic" means the FCL includes a thyristor converter. The method of limiting short-circuit currents via thyristor converters is already known for quite a long time in principle [1], [2]. Thereby FCLs normally are investigated in the case of faults in the electrical system and mostly with respect to their capability of limiting short-circuit currents.

In this first chapter, the power electronic based FCL's capability to limit short-circuit currents will be recapitulated shortly. The real issue of this paper, the control of a power electronic based FCL in operation without a fault, will be discussed in chapter 2 and 3 .

\section{A. The power electronic based FCL}

A basic schematic diagram of a system with an FCL is shown in fig. 1. This could be the auxiliary supply of an electrical power plant for example, wherein the auxiliary grid is simplified and only includes these elements necessary for a basic research. The elements therein are a three-phase positive-sequence mains voltage $u_{p R, S, T}$, a unit auxiliary transformer UAT and a load impedance $Z_{L}$. All elements of a real system, that affect the system's overall short-circuit impedance are converted to a concentrated short-circuit impedance $\underline{Z}_{k}$, which is located on the low voltage side of the transformer. This transformer has to be of Diii-type, so that the FCL can be connected to the open connectors of the secondary windings and build the neutral point of the transformer. Together with the FCL the Diii-transformer works like a Dy5-transformer.

The FCL itself basically consists of a 6-pulse thyristor converter $\mathrm{T}_{1}$ to $\mathrm{T}_{6}$ with an inductor $L_{d}$ on its DC-terminals [1], [2]. The resistance of the inductor is represented via $R_{d}$. The DC-inductor is bypassed by a free-wheeling diode $\mathrm{D}_{\mathrm{FW}}$, which is needed for a minimum system perturbation caused by the FCL. The system's neutral point is provided by the diodes $\mathrm{D}_{7}$ and $\mathrm{D}_{8}$.

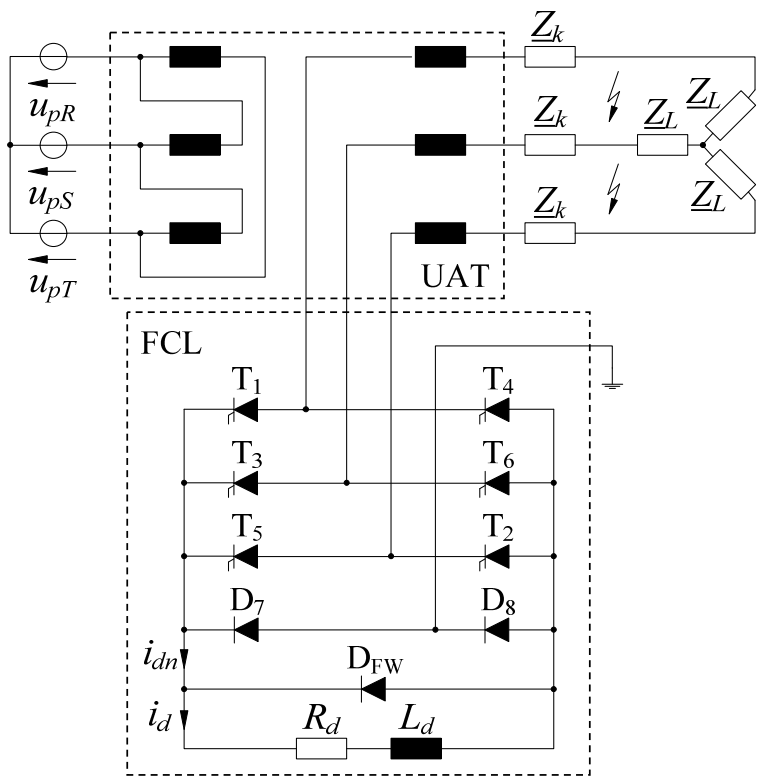

Fig. 1: Basic schematic diagram of the investigated system 
A possible failure location is marked in fig. 1 with two flashes. In case of a short-circuit at this location, the FCL limits the currents with three mechanisms, which have already been shown in [3] and [4] (vide 1. B. to 1. D.):

\section{B. Limitation of the peak short-circuit current}

The inductive component of the DC-inductor $L_{d}$ limits the increase of the short-circuit current because of its self-inductance. So the peak short-circuit current is limited. This effect of the FCL is illustrated in fig. 2, where the normalized time characteristics of the short-circuit currents of a $50 \mathrm{~Hz}$-system with a short-circuit impedance ratio of

$$
\frac{R_{k}}{X_{k}}=\frac{R_{k}}{\omega L_{k}}=0.1
$$

are shown. Therein the time characteristics without FCL are illustrated in grey and the expected value of the normalized peak short-circuit current of about 1.7 can be recognized. For a system including an FCL with a normalized DC-impedance of

$$
\frac{X_{d}}{\left|\underline{Z}_{k}\right|}=\frac{\omega L_{d}}{\left|R_{k}+\mathrm{j} \omega L_{k}\right|}=3
$$

the results are illustrated coloured in fig. 2 and one can see the maximum normalized peak short-circuit current is reduced to a value of about 1.1 .

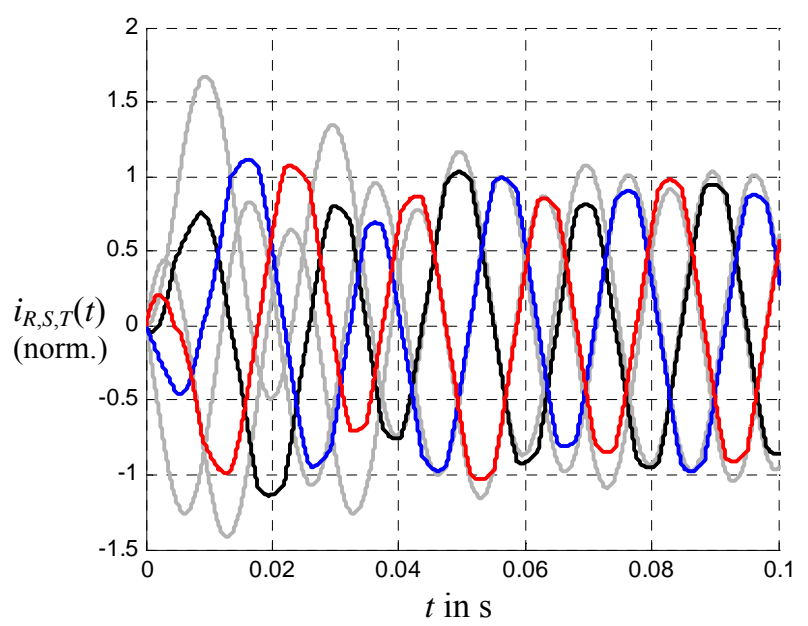

Fig. 2: Normalized time characteristics of the short-circuit currents with FCL (coloured) and without FCL (grey)

\section{Control of the rms-value of the short-circuit currents}

The rms-value of the steady-state short-circuit current can be set up by phase control modulation of the thyristors. This can be seen in fig. 3 where the FCL controls the steady-state currents of a three-phase short-circuit to a normalized rms-value of 0.5 .

For further information on controlling short-circuit currents [5] is recommended.

\section{Short-circuit breaking}

By blocking the firing pulses of the thyristors the short-circuit fault can be cleared in an easy way as seen in fig. 4. Therefor the firing pulses were blocked, after the
DC-current $i_{d n}$ (cf. fig. 1) reached an instantaneous value of 0.3 (normalized). This offers the possibility of a very fast fault clearing.

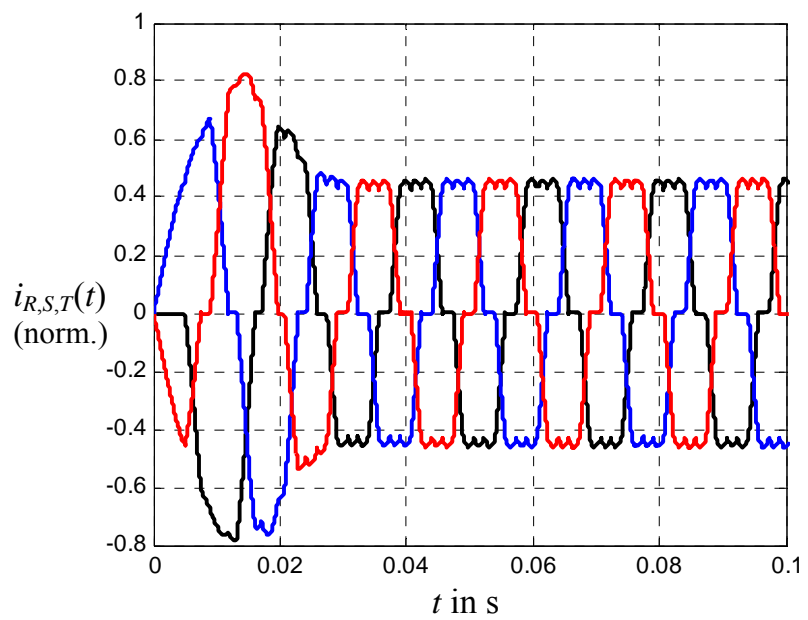

Fig. 3: Normalized time characteristics of controlled short-circuit currents

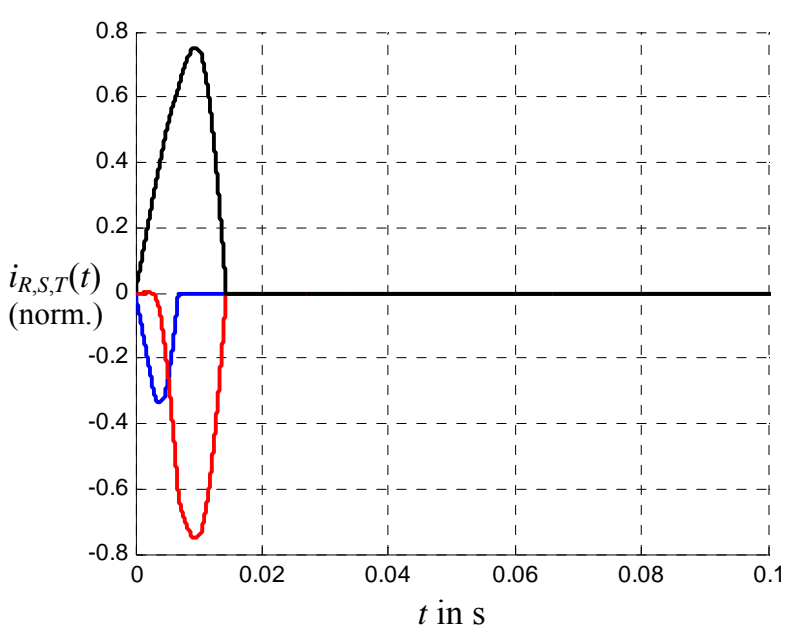

Fig. 4: Normalized time characteristics of a three-phase short-circuit with clearing by firing plus blocking

\section{E. Other possibilities}

As already mentioned in 1. D. a short-circuit detection can easily be realized simply by measuring the direct current $i_{d n}$. If this current exceeds a certain threshold value defined by the system, it can be assumed a short-circuit occurred. Furthermore, by a combination of the peak current limitation (vide 1. B.) and a fast fault clearing (vide 1. D.) the incident energy of electrical arcs can be limited effectively [6].

\section{Control of the FCL in a balanced system without a fault}

Now having recapitulated the FCL's possible applications in limiting short-circuit currents in the previous chapter, in this chapter the control of the FCL in the normal operation without a fault ("no-fault operation") will be discussed. Thereby in a first step a balanced three-phase system is investigated. Unbalanced systems will be investigated in chapter 3 . 


\section{A. Challenge on a controller}

In faultless operation all currents of an electrical $50 \mathrm{~Hz}$-system should show a sinusoidal waveform. The existence of an FCL in the system should ideally not influence this fact. So in no-fault operation the control of the FCL has to provide a sinusoidal waveform for all currents of an electrical three-phase system including an FCL. This is basically the challenge of this work: guaranteeing sinusoidal waveforms.

As already mentioned in 1. C. the only possibility of the FCL to have influence on the system's steady-state currents is by phase control modulation of the thyristors (cf. fig. 3: $0.03 \mathrm{~s}<t<0.1 \mathrm{~s}$ ). This leads to non-sinusoidal current waveforms, where at least one of the currents is equal to zero for a certain period of time. In contrast, sinusoidal currents are never equal to zero for a period of time. A sinusoidal shaped current is equal to zero only during its zero crossing, which ideally does not last for a period of time, but only for an infinitesimal short moment. These characteristic differences between a phase modulation controlled current and a sinusoidal current can now be used to control the FCL to provide sinusoidal currents. Therefor the periods of time, where one of the currents is equal to zero ("non-conducting states") have to be detected.

\section{B. Reference signal for non-conducting states}

To be able to detect non-conducting states firstly one has to think a about a reference signal. Therefore fig. 5 shows an image enlargement of a normalized sinusoidal current wherein two limits are marked symmetrically to the zero line. In this example these markings are at

$$
i(t)= \pm 0.1 \text {. }
$$

The corresponding points in time are

$$
\begin{gathered}
t_{1}=\sin ^{-1}(-0.1) \approx-0.32 \mathrm{~ms}, \\
t_{2}=\sin ^{-1}(0.1) \approx 0.32 \mathrm{~ms} .
\end{gathered}
$$

With these, a period in time wherein the normalized current is within a range of \pm 0.1 can be defined (cf. fig. 5):

$$
\Delta t_{0.1}=t_{2}-t_{1} \approx 0.64 \mathrm{~ms} \text {. }
$$

The current limits of eq. (3) have been chosen for a better recognisability in the figure only. Investigations have proven a reasonable value for the current limits is

$$
i(t)= \pm 0.5 \%
$$

which is again normalized to the amplitude of the sinusoidal current. So the corresponding time period is

$$
\Delta t_{0.5 \%}=\sin ^{-1}(0.005)-\sin ^{-1}(-0.005) \approx 0.032 \mathrm{~ms}
$$

or normalized to the maximum non-conducting duration within a half period of $10 \mathrm{~ms}$

$$
\Delta t_{0.5 \%, \text { norm. }}=\frac{0.032 \mathrm{~ms}}{10 \mathrm{~ms}}=0.32 \% .
$$

With eq. (9) it is known that a sinusoidal current is within a normalized range of $\pm 0.5 \%$ during a normalized time of $0.32 \%$. This understanding can now be used to control the non-conducting states of the FCL.

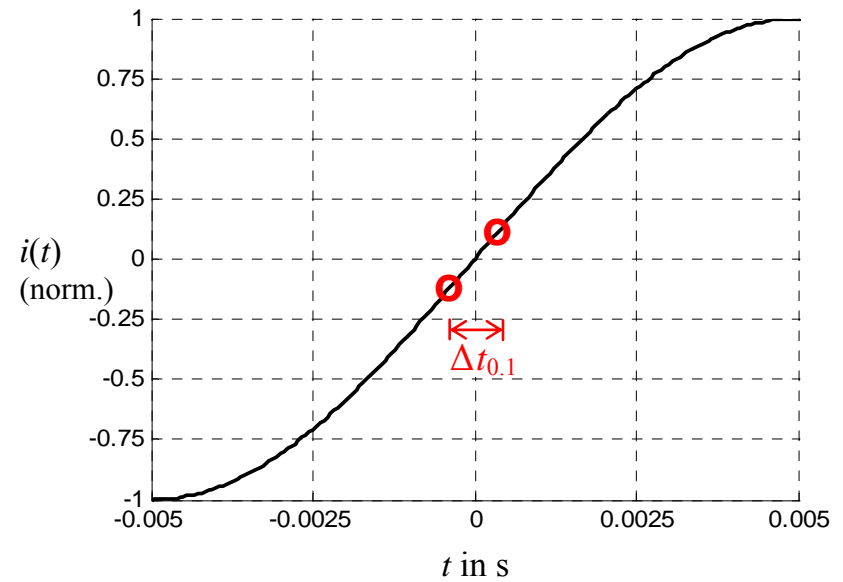

Fig. 5: Normalized sinusoidal current

\section{Detection of non-conducting states}

With the knowledge of eq. (9) now it is possible to derive a method for detecting non-conducting states of the FCL. This will be explained via a possible implementation in Matlab/Simulink that is shown in fig. 6.

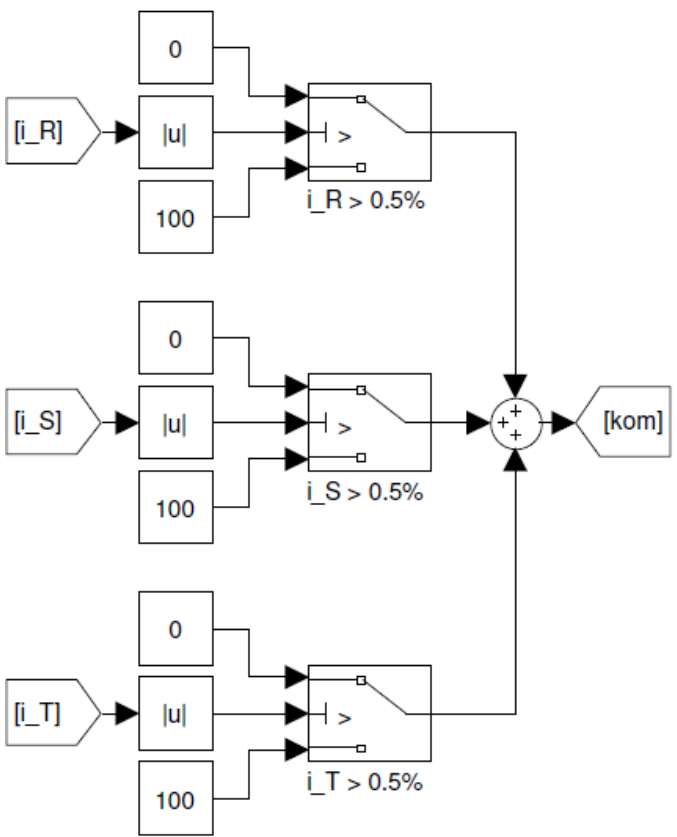

Fig. 6: Detection block for non-conducting states in Matlab/Simulink

After the line currents have been rectified using absoluteblocks (cf. fig. 6: $|\mathrm{u}|$ ) every current is connected to the decision terminal of a switch. These are parameterized in a way that a switch outputs 100 as long as the corresponding current is below the threshold level of $0.5 \%$ (cf. eq. (7)). Is the normalized current higher than $0.5 \%$ the output is 0 . The three signals are added, so that the output signal of the block (fig. 6: kom) can be in the range of

$$
k o m \in[0 ; 300] .
$$

The kom-signal is equal to zero at every point in time, where none of the three currents is within the limits of eq. (7): 


$$
\left.\begin{array}{rl}
\left|i_{R}(t)\right|>0.5 \% & \wedge\left|i_{S}(t)\right|>0.5 \% \\
& \wedge\left|i_{T}(t)\right|>0.5 \%
\end{array}\right\} \Rightarrow \operatorname{kom}(t)=0
$$

As the detection block of fig. 6 builds the sum of the three conducting signals, the value of eq. (9) (which is valid only for a single sinusoidal waveform) has to be multiplied by 3 . So one knows, for sinusoidal currents in the steady-state the average mean value of the kom-signal has to be

$$
\operatorname{mean}(\operatorname{kom}(t))=3 \cdot 0.32 \%=0.96 \% .
$$

This is the setpoint for the controller.

\section{Controller for sinusoidal currents and results}

Fig. 7 shows the control structure for sinusoidal currents implemented in Matlab/Simulink. On the left the error signal is built as the difference of the setpoint value $0.96 \%$ and the kom-signal.

The error signal is fed to a PI-controller. This is advantageous because a PI-controller per se comprises an averaging as stated in eq. (12). Its controller gain and time constant have been derived in [5], but because of the highly variable time characteristic of the kom-signal (cf. fig. 9) here the gain has to be reduced by the factor 10 :

$$
K_{p}=0.18, T_{N}=0.00 \overline{3} \mathrm{~s} .
$$

To ensure that the currents are not sinusoidal directly from the beginning of the simulation, an offset of $110^{\circ}$ is added to the output of the controller. The firing angle is then fed to the trigger equipment.

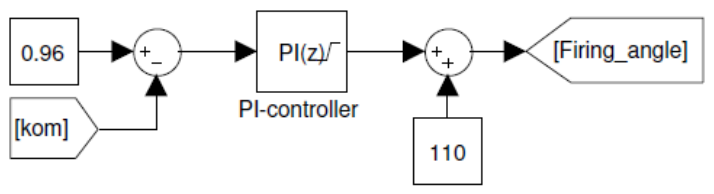

Fig. 7: Control structure for sinusoidal currents

The results are shown in fig. 8 for an FCL's DC-inductor according to eq. (2). It can be seen, the controller performs like designated: Starting with non-sinusoidal currents, the currents are sinusoidal after about 140ms.

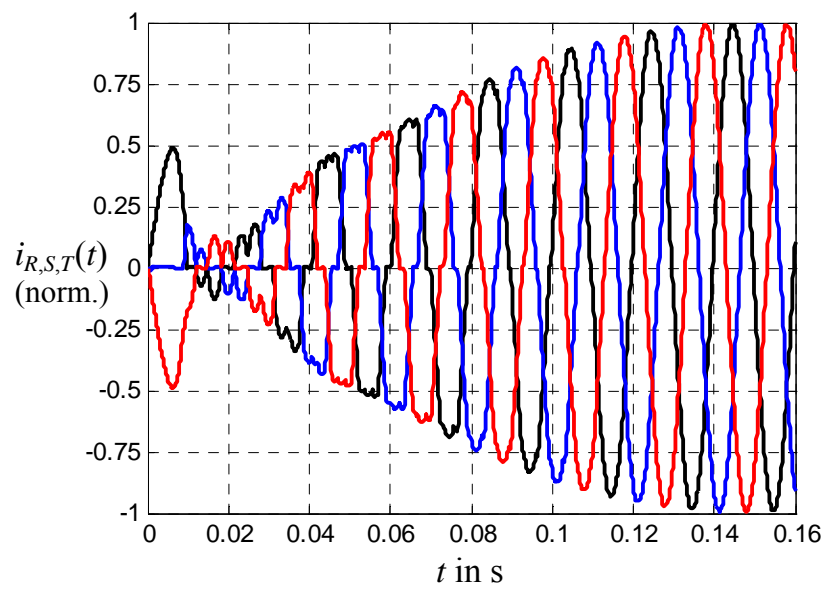

Fig. 8: Time characteristics of the controlled currents
Fig. 9 shows the time characteristics of the kom-signal and the firing angle. It can be recognized the firing angle is controlled from the initial value of $110^{\circ}$ to its steady-state value of $57^{\circ}$, which provides sinusoidal currents. Furthermore one can seen, the average mean value of the kom-signal goes down. It can be proven by computer calculation of its time characteristic, in the steady-state the mean value of the kom-signal is in the region of its setpoint of $0.96 \%$.

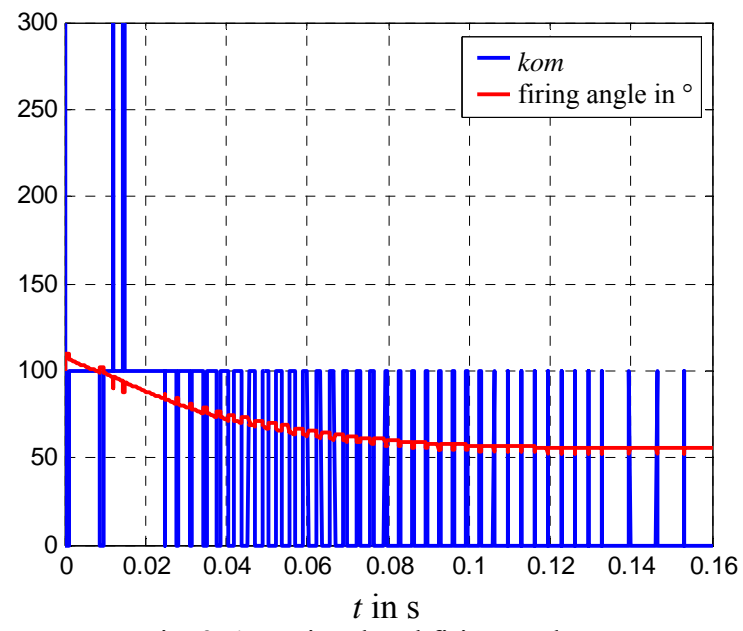

Fig. 9: kom-signal and firing angle

\section{Control of the FCL in operation without a fault and under unbalanced conditions}

The approach now demonstrated for a balanced system can easily be extended to systems where unbalances have to be expected. Those unbalances in an electrical three-phase system can be caused by an unbalanced mains voltage or unbalanced loads, for example. In this paper only 2-pulse type unbalances (time characteristics show a symmetry of $10 \mathrm{~ms}$ ) are considered.

\section{A. Principle approach for unbalanced systems}

To be able to handle unbalanced electrical three-phase systems with a power electronic based FCL, the same approach as drafted in chapter 2 can be used in principle. The only difference is, the methods already shown have to be applied individually for every phase.

Therefor fig. 10 shows a modified detection block for non-conducting states. Basically it is the same as the already known block of fig. 6 , only with three individual kom-signals.

These individual kom-signals are given to three individual controllers as shown in fig. 11. Now as every phase is controlled individually, the setpoint is not longer given by eq. (12), but by eq. (9). For the same reason the controller time constant has to be reduced to

$$
T_{N}=0.001 \mathrm{~s}
$$

and a modified trigger equipment has to be used that allows individual firing angles for the three legs of the current converter. So the firing angle for line $\mathrm{R}$ only controls the thyristors $\mathrm{T}_{1}$ and $\mathrm{T}_{4}$, for example. 

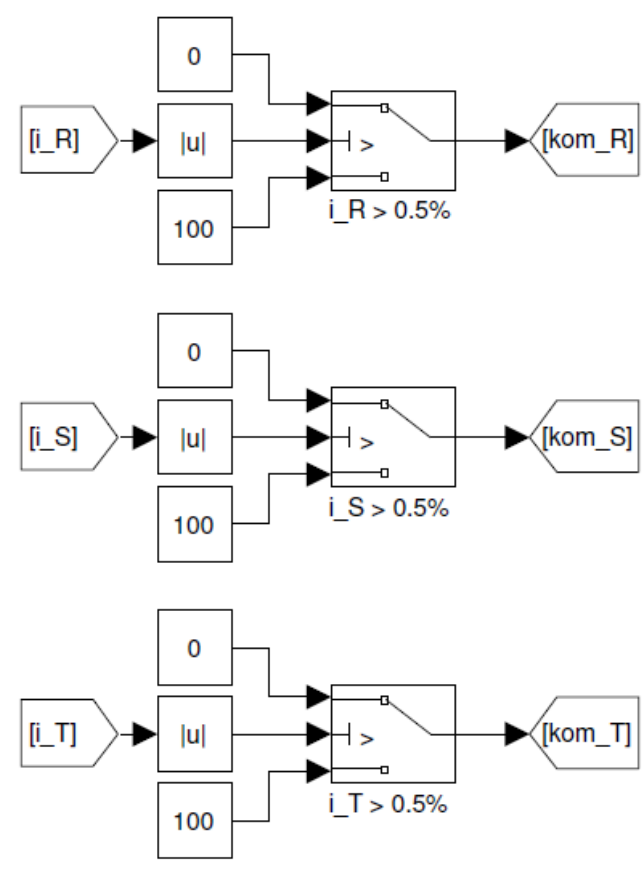

Fig. 10: Detection block for non-conducting states for unbalanced conditions in Matlab/Simulink
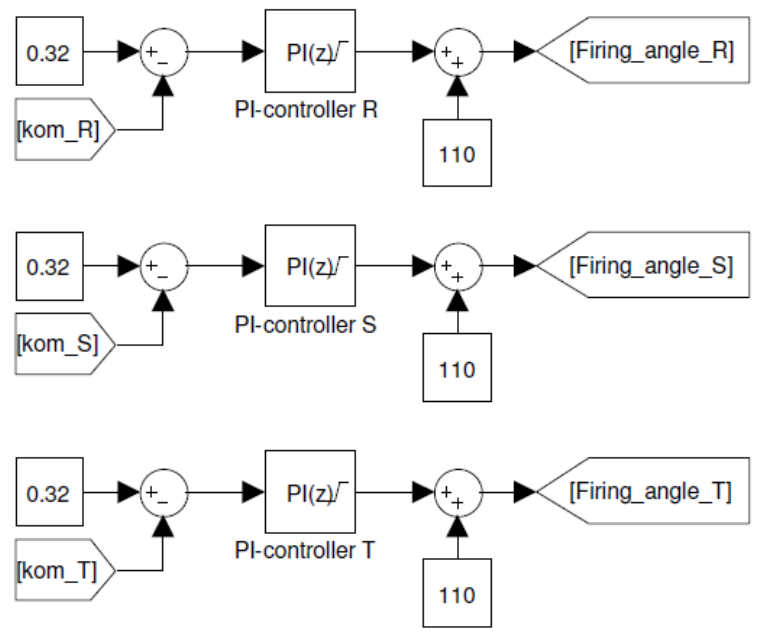

Fig. 11: Control structure for sinusoidal currents in unbalanced systems

\section{B. Results for unbalanced loads}

The drafted approach for unbalanced electrical three-phase systems is now executed for a system with unbalanced load impedances:

$$
\begin{aligned}
& \underline{Z}_{L, R}=1.5 \cdot \underline{Z}_{L, S}, \\
& \underline{Z}_{L, T}=\underline{Z}_{L, S} / 1.5 .
\end{aligned}
$$

Fig. 12 shows the normalized time characteristics of the load currents for the unbalanced loads according to eq. (15) and (16). After about $160 \mathrm{~ms}$ the currents have reached their sinusoidal steady-state waveform.

It can be shown that the approach for unbalances in electrical three-phase systems does not only work for the presented example of unbalanced loads. It is also applicable to every other 2-pulse type unbalance condition, like an unbalanced mains voltage or unbalanced short-circuit impedances.

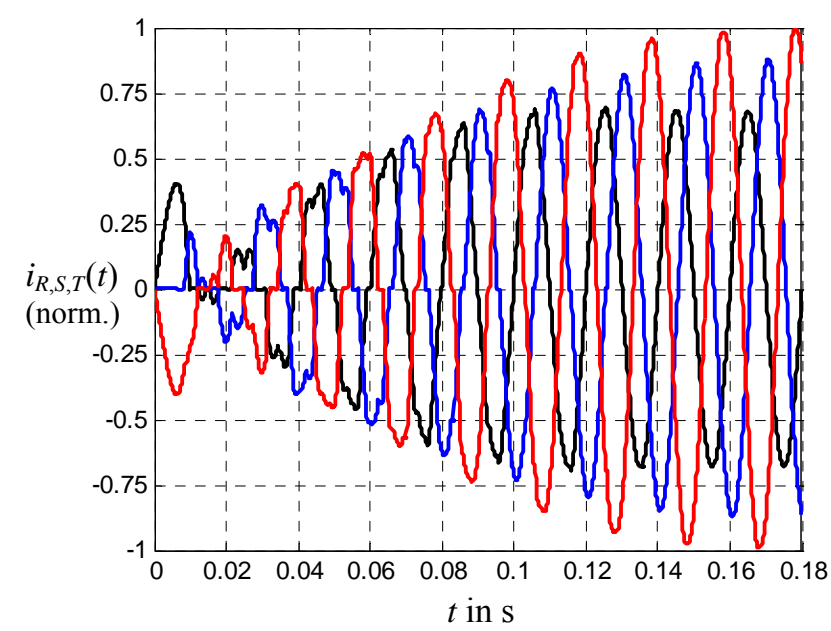

Fig. 12: Time characteristics of the controlled currents

\section{Conclusion}

Control strategies for a power electronic based fault current limiter in normal operation without a fault have been presented. After developing a method for detecting non-conducting states, control strategies have been derived. It could be shown, appropriate ways of controlling a power electronic based fault current limiter were found. This has been done successfully for balanced electrical three-phase systems, as well as for unbalanced systems.

\section{References}

[1] W. Schulze-Buxloh, "Limitation of peak short-circuit currents in three-phase systems (Begrenzung von Stoßkurzschlußströmen in Drehstromnezten)", ETZ-A, vol. 95, 1974, pp. 426-427 (in german)

[2] G. Herold, L. Gebhardt, V. Pfeiler, "Short-circuit current limitation in three-phase systems by means of inverters in bridge circuit (Kurzschlußstrombegrenzung in Drehstromsystemen mit Stromrichtern in Brückenschaltung)“, Electrie, vol. 34, 1980, pp. 554-556 (in german)

[3] S. Palanichamy, P. Chinnasamy, "Semiconductor faultcurrent limiters - pt. 3: Investigation on microprocessor-based thyristor fault-current limiter for use in power systems", IEEE Proc. Gen. Trans. \& Distrib., vol. 131, pt. C, no. 3, 1984, pp. 103-106

[4] H. Rubenbauer, G. Herold, "A dynamic fault current limiter (DFCL)", IEEE PES PowerAfrica Conf., Johannesburg (South Africa), 2007, paper 127

[5] C. Hahn, M. Weiland, G. Herold, "Control design for a power electronic based fault current limiter (FCL)", International Conf. on Renewable Energies and Power Quality (ICREPQ), Santiago de Compostela (Spain), 2012

[6] M. Weiland, A. Schön, G. Herold, "Application of a power electronic based fault current limiter (FCL) to reduce arc flash energy in electrical grids with high short-circuit power", 14th European Conf. on Power Electron. and Applicat. (EPE), Birmingham (UK), 2011 